\title{
Health promotion and dental caries ${ }^{\S}$
}

\section{Marisa Maltz(a) \\ Juliana Jobim Jardim ${ }^{(b)}$ \\ Luana Severo Alves(c)}

(a) PhD, Professor; (b) PhD; (c) MSc, Graduate Fellow - Department of Social and Preventive Dentistry, School of Dentistry, Federal University of Rio Grande do Sul, Porto Alegre, RS, Brazil. §aper presented at the "Promotion of Oral Health in the Public and Private Context" National Symposium, held at the $15^{\text {th }}$ Congress of the Brazilian Association for Oral Health Promotion (ABOPREV), May 27-29, 2010, Brasília, DF, Brazil.

\section{Corresponding author:}

Marisa Maltz

Faculdade de Odontologia - UFRGS

Departamento de Odontologia Preventiva e Social

Rua Ramiro Barcelos, 2492, Bom Fim

Porto Alegre - RS - Brazil

CEP: 90035-003

E-mail:marisa.maltz@gmail.com

Received for publication on Jul 05, 2010

Accepted for publication on Aug 02, 2010
Abstract: The central idea of the Brazilian health system is to prevent the establishment of disease or detect it as early as possible. Prevention and treatment of dental caries are related to behavioral factors, including dietary and oral hygiene habits, which are related to many chronic diseases. Dental health promotion therefore should be fully integrated into broadly based health-promoting strategies and actions such as food and health policies, and general hygiene (including oral hygiene), among others. For decades, a linear relationship between sugar consumption and caries has been observed. Recent data has indicated that this relationship is not as strong as it used to be before the widespread use of fluoride. However, diet is still a key factor acting in the carious process. Oral hygiene is a major aspect when it comes to caries, since dental biofilm is its etiological factor. Oral hygiene procedures are effective in controlling dental caries, especially if plaque removal is performed adequately and associated with fluoride. An alternative to a more efficient biofilm control in occlusal areas is the use of dental sealants, which are only indicated for caries-active individuals. If a cavity is formed as a consequence of the metabolic activity of the biofilm, a restorative material or a sealant can be placed to block access of the biofilm to the oral environment in order to prevent caries progress. The prevention of dental caries based on common risk-factor strategies (diet and hygiene) should be supplemented by more disease-specific policies such as rational use of fluoride, and evidence-based dental health care.

Descriptors: Health Promotion; Primary Health Care; Dental Caries; Diet; Oral Hygiene.

\section{Introduction}

Dental caries is defined as a chemical dissolution of the tooth mineral resulting from metabolic events taking place in the dental biofilm covering the affected area. These events are the caries process, while the resulting caries lesion is the sign of the disease. Some components of the caries process act at the tooth surface (saliva, biofilm, diet, fluoride), while another set of determinants of the process act at the individual level (a person's behavior, knowledge, attitude, education, socioeconomic status, income). The disease processes leading to dental caries must undergo lifelong control in order to avoid irreversible consequences in the later stages of caries development, namely cavity formation, restoration, endodontic treatment, crown therapy and possibly the ultimate loss of the tooth. ${ }^{1}$ By controlling the caries process, it is possible to prevent the occurrence of its signs (caries lesion). In Dentistry, dental caries is 
the most prevalent disease and the major reason for tooth loss, ${ }^{2}$ representing a major challenge for oral health care. The central idea of the Brazilian health system is to prevent the establishment of disease or detect it as early as possible, in a way that the problem can be resolved at a primary care level, and that only a small proportion of cases need to be routed to the secondary care level. One of the great advantages of this approach is the ability to adopt more conservative, less invasive treatments than would be required at a later stage of development, thus preserving tooth structure. In addition to this biological advantage, it is well known that secondary care is much more costly than primary care and tends to involve a greater use of technologies. ${ }^{3}$

In this article we discuss health promotion related to dental caries, and the need to apply a common risk approach to prevention. Health promotion cannot be compartmentalized to the specific parts of the body. Dental health promotion should be fully integrated into broadly based health-promoting strategies and actions. These health-promoting strategies should be supplemented with more disease-specific policies. ${ }^{4}$ These disease-specific strategies directed to dental caries prevention will be further analyzed.

The new knowledge flowing from the dramatic increase in biomedical research productivity since World War II, the technology deriving from those advances, and a widespread desire among professionals for expertise have led to an increasing trend towards specialization. ${ }^{3}$ In Brazil, from 2003 to 2007, the number of dental specialists increased from 1,291 to 5,165 in the South Region, representing a four-fold increase. ${ }^{5}$ Nowadays, around $27 \%$ of the professionals enrolled in the Federal Council of Dentistry ${ }^{6}$ are specialists, and it appears that this proportion will continue to increase linearly over the years. Undoubtedly, specialty expertise has offered clinical benefits to thousands of patients, especially those with uncommon or critical disorders or requiring special techniques. On the other hand, it is clear that specialist practices have little effect on the dental health of the overall population. Ecological analyses indicate that social factors, rather than dental service, explain most of the geographic variation in caries prevalence. ${ }^{7}$ Nadanovsky and
Sheiham ${ }^{8}$ demonstrated that dental service could explain only about $3 \%$ of the differences observed in the caries level among 12 year-olds across 18 countries. Most of the differences in oral health were due to broad socioeconomic factors.

Bearing this principle in mind, oral health promotion should be integrated in general health promotion strategies. Oral diseases such as dental caries and periodontitis and systemic diseases such as cancer, type 2 diabetes, obesity and cardiovascular disease are similar regarding their chronicity and their multifactorial and behavioral characteristics. Two kinds of interaction between oral and systemic disorders can be distinguished: they may have etiological/risk factors in common, or one may be, itself, an etiological/risk factor for the other.

In order to exemplify the first situation, let us consider sugar consumption. It is clear in the literature that sugar consumption is associated with dental caries ${ }^{9}$ and obesity. ${ }^{10}$ This, in turn, is a recognized risk factor for the development of type 2 diabetes ${ }^{11}$ and cancer. ${ }^{12}$ Hence, the adoption of healthy dietary habits, with a controlled sugar intake, could improve both oral and general health. Similarly, smoking is an important risk factor for periodontitis ${ }^{13}$ and tooth loss ${ }^{14}$ as well as for a variety of cancers, ${ }^{15-17}$ and smoke cessation would bring endless benefits to the health of the mouth and of the whole body.

The second situation can be exemplified by the relation between periodontitis and maternal outcomes. Studies have shown that maternal periodontal disease can be a risk factor for preterm birth and low birth weight, ${ }^{18,19}$ evidencing that an oral condition could be associated with a systemic effect. Conversely, systemic conditions can also cause oral effects. Xerostomia or hyposalivation as a result of head and neck irradiation or as a consequence of systemic diseases or medications may be related to higher caries experience; ${ }^{20,21}$ type 2 diabetes $^{22}$ and obesity $^{23}$ may increase the risk of developing periodontal disease. Many other examples could be cited here, stressing the strong relationship between oral and systemic health. Therefore, in a context of health promotion, dental professionals should be aware of this relation, and use this knowledge to im- 
prove their actions, both preventive and therapeutic. Oral health promotion strategies to prevent and control oral diseases should be part of a common risk factor approach to control the risks shared by a number of chronic diseases. Such strategies include food and health policies to change unhealthy dietary practices, general hygiene (including oral hygiene), tobacco consumption, and control of accidents (traumatic dental injuries), among others. These strategies should be supplemented by more disease-specific policies such as rational use of fluoride, and evidence-based dental health care.

The two major factors associated with dental caries, diet and biofilm, will be further analyzed. The access to and benefits of fluoride will not be discussed in the present article since this topic is presented elsewhere in this issue by Prof. Cury.

\section{Diet and health promotion}

Sugar consumption can be considered one of the primary etiological factors of dental caries, and without the presence of fermentable carbohydrates, disease does not develop. Although many classic studies have already demonstrated the association between sugar consumption and caries (Turku Sugar Study, ${ }^{24}$ Hopewood House Study, ${ }^{25}$ Hereditary Fructose Intolerance ${ }^{26}$ and Experimental Caries in $\operatorname{Man}^{27}$ ), the Vipeholm Study definitively established that the more frequently sugar is consumed, the greater the caries risk. ${ }^{9}$

For some decades, a linear relationship between sugar consumption and caries experience has been observed, ${ }^{28}$ and restricting sugar intake has played an important role in caries prevention. More recent data, however, has indicated that this relationship is not as strong as it used to be before the widespread use of fluoride. A recent systematic review aimed to answer the question "In the modern age of extensive fluoride exposure, do individuals with a high level of sugar intake experience greater caries severity relative to those with a lower level of intake?". ${ }^{29}$ After the assessment and categorization of 36 manuscripts according to the strength of association (weak for Odds Ratio/Relative Risk $\leq 1.4$, moderate for OR/RR between 1.5 and 2.4, and strong for OR/ $R R \geq 2.5$ ), the authors concluded that the relation between sugar and caries is much weaker than it was before the fluoride era. Clearly, with the advent of fluoride in drinking water and in toothpastes, a higher cariogenic diet can be tolerated before caries occurs in many individuals. However, fluoride has its limits, and caries remains a serious problem, especially for economically disadvantaged individuals, since in this group sugar consumption is increasing but fluoride use has not been widely adopted..$^{30}$

Caries-active patients probably present the dietary component strongly involved in the carious process. It is necessary to evaluate patients' dietary habits in order to propose realistic changes that may lead to the reestablishment of the balance between demineralization and remineralization. Advice to restrict the consumption of sugary snacks and drinks is part of general dietary counseling ${ }^{31}$ since diet is a common risk factor for other chronic diseases such as obesity and diabetes. Although some cutoff values have been suggested for the maximum frequency and amount of sugar to be consumed in order to prevent tooth decay $(<4$ times/day; $<60 \mathrm{~g} /$ day), ${ }^{32}$ one must remember that dental caries is a multifactorial disease, and other factors such as oral hygiene and access to fluoridated products are also determinants of the carious process and should be addressed for caries prevention and treatment.

\section{Biofilm control and heath promotion}

Oral hygiene is a major factor when it comes to caries prevention and treatment, since dental biofilm, as well as sugar, is one of the etiological factors of this disease. The study of von der Fehr et al. ${ }^{27}$ (Experimental Caries in Man) showed that the lack of oral hygiene, during 23 days, associated with a high sugar exposure, produced clinically detectable caries lesions. The reversal of the lesions was also achieved when oral hygiene was performed associated with daily mouthrinses with fluoride solutions. Holmen et al..$^{33}$ showed that the control of caries lesions can be obtained solely by plaque removal, without the use of fluoride. Nowadays, the effect of oral hygiene per se on dental caries is difficult to be determined, since many studies are confounded by the current use of fluoridated dentifrices. ${ }^{31}$ How- 
ever, in regions where there is limited access to fluoride and to dental services, the role of oral hygiene in preventing dental caries can still be determined. In a clinical study conducted to determine risk indicators of dental caries in the permanent dentition, the only variable that was found to be a consistent risk indicator of the presence and severity of both dentine and enamel caries was poor oral hygiene. ${ }^{34}$ In two other studies, one of them performed in Brazil, risk indicators of the prevalence and incidence of dental caries were analyzed in children and adults, and a low frequency of toothbrushing (< two times/ day) was significantly associated with dental caries and with a lower number of sound teeth. ${ }^{35,36}$

The effect of preventive programs including oral hygiene measures on caries increments has been reported both as successful ${ }^{37}$ and unsuccessful. ${ }^{38}$ In the Karlstad Program, regular professional plaque removal was part of a preventive program applied to a group of schoolchildren with high caries prevalence. ${ }^{37}$ In addition to parent engagement and diet counseling, professional tooth cleaning with fluoridated dentifrice and oral hygiene instructions were carried out. The program resulted in a high level of oral cleanliness and a significant reduction in dental caries. Results of 30 years of maintenance of these individuals indicated a low incidence of caries, periodontal disease and tooth loss, confirming the longterm benefit of maintaining a high standard of oral hygiene. ${ }^{39}$ In caries control, the effect of oral hygiene programs that require the individuals' compliance is more difficult to achieve. Maltz ${ }^{38}$ conducted a controlled clinical trial in which schoolchildren were submitted to a preventive program that included weekly sessions of supervised oral hygiene (tooth brushing with non-fluoride dentifrice and dental flossing), as well as diet counseling and oral hygiene instructions. After 14 months, despite the decrease in gingivitis (increase in dental plaque control), lack of significant differences between the test and control groups regarding caries incidence was observed. A systematic review examined the effectiveness of oral health promotion on caries and found that very few definitive conclusions could be drawn from the currently available evidence. ${ }^{40}$ Caries and periodontal disease can be controlled by regular tooth- brushing with fluoridated toothpaste, but a cost-effective method for reliably promoting this behavior has not yet been established. Chair-side oral health promotion has been shown to be effective more consistently than other methods of health promotion. Mass-media programs have not been shown to be effective. Based on these studies, it seems that preventive programs including professional plaque removal/supervision are only justified in groups with high caries activity.

Besides tooth brushing, oral hygiene procedures include dental flossing. The relationship between dental flossing and interproximal caries risk was studied in a systematic review of the literature. ${ }^{41} \mathrm{Six}$ trials were selected and all of them were performed in children. Two studies showed a significant reduction in dental caries $(40 \%)$ on primary teeth using professional cleaning 5 days/week during 1.7 year. The other four articles included professional and self-performed flossing and did not show a reduction in caries risk. No flossing trials in adults or under unsupervised conditions could be identified. This review concluded that professional flossing in young children with low fluoride exposure is effective in reducing interproximal caries. However, this result cannot be extrapolated to real life conditions, since self-flossing has failed to show a significant effect. Also, the success of interdental cleaning is greatly dependent on ease of use and patient compliance. ${ }^{42}$

In conclusion, oral hygiene procedures are effective in controlling dental caries, especially if plaque removal is performed adequately and associated with fluoride. Programs using professional or supervised tooth cleaning can also be effective; however, one must take into account the need for patient compliance and training.

On the occlusal surface of molars, dental biofilm removal is difficult to perform because of the anatomic characteristics of its pits and fissures. As a result, biofilm removal is not always achieved in an effective way. An alternative to allow a more efficient biofilm control in this area is the use of dental sealants. ${ }^{43}$ The sealing of occlusal surfaces in a preventive approach has shown positive results (caries risk reduction of $33-65 \%) ; 4-48$ however, it will depend on a series of variables. Ahovuo-Saloranta et 
al. ${ }^{48}$ through a systematic review of the literature, showed that the effectiveness of sealants is obvious for high caries-risk individuals, but information on the benefits of sealing to patients with different caries-risk levels is lacking. The material used to seal the surface is also an important factor, and resinbased sealants are preferable when compared to glass ionomer cement. ${ }^{45}$ Loss or fracture of sealants should be considered, since a significant relation has been established between intact sealants and a reduction in caries risk. ${ }^{45}$ There is evidence indicating that a much better effect is observed if re-sealing is performed. Mejàre et al..$^{45}$ observed in a systematic review that a single sealant application produced a relative risk reduction ranging from $4-54 \%$, whereas the reduction produced by repeated sealing ranged from $69-93 \%$. In conclusion, the use of sealants as a preventive measure for dental caries is indicated in caries-active individuals, resin-based sealants should be preferred, and, once the sealant is placed, it must be checked regularly.

If plaque removal is not performed with a certain frequency and a cavity is formed, this site provides an ecological niche in which the biofilm microorganisms gradually adapt to a low $\mathrm{pH}$. The cavity protects the biofilm and, unless the patient is able to clean this area, the caries process will progress. ${ }^{31}$ In order to detain the lesion's progress, a restorative material or a sealant can be placed to block access of the biofilm to its main source of nutrition, the oral environment, thus trapping it in the cavity. This approach is considered a reliable measure to control the carious process. ${ }^{49}$

Several studies evaluating microorganism survival under sealants and restorations have been conducted. ${ }^{50-55}$ The results showed a significant reduction in the total amount of bacteria and a modification of the composition of the cariogenic biofilm after sealing the carious dentine. ${ }^{50,52,55}$ Oong et al. ${ }^{56}$ performed a meta-analysis on the effect of dental sealants on bacteria levels in caries lesions. Six studies were included in the analysis and the results showed that there was no evidence of significant bacteria proliferation under sealants. Sealing caries was associated with a 100 -fold reduction in mean total CFU. Furthermore, sealants reduced the prob- ability of viable bacteria by about $50 \%$ (four studies, 117 samples).

Mertz-Fairhurst et al. ${ }^{57}$ performed a long-term study in which the complete removal of carious dentine prior to restoration was compared with the sealing of carious tissue beneath the filling material. The 10-year study evaluated bonded and sealed composite restorations placed directly over cavitated lesions extending into the dentin outer half versus sealed conservative amalgam restorations and conventional unsealed amalgam restorations. The results showed that the bonded and sealed composite restorations placed over cavitated lesions arrested the clinical progress of these lesions for 10 years. ${ }^{58}$

In studies using a partial removal of carious dentine or the stepwise excavation technique, authors reported that the dentine left on the bottom of the cavity presented signs of arrestment after a certain period of time: the tissue became harder, drier and with a significant reduction in bacterial contamination. ${ }^{59-65}$ This evidence leads to the conclusion that it is possible to control caries progression if the biofilm present in the cavity can be isolated from the oral environment or if it can be mechanically removed by the patient.

\section{Conclusions}

- Health promotion cannot be compartmentalized to specific parts of the body. Dental health promotion should be fully integrated into broadly based health-promoting strategies and actions.

- Diet, hygiene, tobacco, alcohol and stress are common causes to many chronic diseases such as cancer, periodontitis, dental caries, cardiovascular disease, diabetes, obesity and psychiatric diseases. A common risk factor approach should be used to prevent these diseases.

- The relationship between sugar consumption and dental caries is not as strong as it used to be before the widespread use of fluoride. Diet is still a key factor acting in the caries process. Advice on the rational consumption of sugar should be given to patients as a part of general dietary counseling.

- Oral hygiene procedures are effective in controlling dental caries, especially if plaque removal is 
performed adequately and associated with fluoride. Programs using professional or supervised tooth cleaning can also be effective; however, one must take into account the patient's caries activity, and the need for his/her compliance and training.

- An alternative to a more efficient biofilm control in occlusal areas is the use of dental sealants, which are only indicated for patients with caries activity.

\section{References}

1. Griffin S, Griffin P, Swann J, Zlobin N. New coronal caries in older adults: implications for prevention. J Dent Res. 2005;84(8):715-20.

2. Brasil. Ministério da Saúde. Projeto SB Brasil - Condição de Saúde Bucal da População Brasileira: 2002-2003. Brasília: Editora MS; 2003.68 p.

3. Barondess J. Specialization and the physician workforce: drivers and determinants. JAMA. 2000;284(10):1299-301.

4. Baelum V, Sheiham A, Burt B. Caries control for populations. In: Fejerskov O, Kidd E, editors. Dental caries: the disease and its clinical management. $2^{\text {nd }}$ ed. Oxford: Blackwell Munksgaard; 2008. p. 506-26.

5. Paranhos L, Ramos A, Scanavini M, Ricci I. [An analysis of the dentistry job market in the Southeast region of Brazil]. Rev Assoc Paul Cir Dent. 2009;63(1):57-63.

6. Federal Council of Dentistry. [cited 2010 June 19]. Available from: www.cfo.org.br.

7. Nadanovsky P, Sheiham A. The relative contribution of dental services to the changes and geographical variations in caries status of 5- and 12-year-old children in England and Wales in the 1980s. Community Dent Health. 1994;11(4):215-23.

8. Nadanovsky P, Sheiham A. Relative contribution of dental services to the changes in caries levels of 12 -year-old children in 18 industrialized countries in the 1970s and early 1980s. Community Dent Oral Epidemiol. 1995;23(6):331-9.

9. Gustafsson BE, Quensel CE, Lanke LS, Lundqvist C, Grahnen $\mathrm{H}$, Bonow BE, et al. The Vipeholm dental caries study; the effect of different levels of carbohydrate intake on caries activity in 436 individuals observed for five years. Acta Odontol Scand. 1954;11(3-4):232-64.

10. Swinburn B, Caterson I, Seidell J, James W. Diet, nutrition and the prevention of excess weight gain and obesity. Public Health Nutr. 2004;7(1A):123-46.

11. Steyn N, Mann J, Bennett P, Temple N, Zimmet P, Tuomilehto $\mathrm{J}$, et al. Diet, nutrition and the prevention of type 2 diabetes. Public Health Nutr. 2004;7(1A):147-65.
- If a cavity is formed as a result of the carious process, a restorative material or a sealant can be placed to block access of the biofilm to the nutrients from the oral environment. Studies on sealed carious dentine show arrestment of the carious process, with harder and dryer dentin (characteristic of arrested lesions), a reduction in the amount of bacteria and an increase in mineral content.

12. Key T, Schatzkin A, Willett W, Allen N, Spencer E, Travis R. Diet, nutrition and the prevention of cancer. Public Health Nutr. 2004;7(1A):187-200.

13. Susin C, Valle P, Oppermann R, Haugejorden O, Albandar J. Occurrence and risk indicators of increased probing depth in an adult Brazilian population. J Clin Periodontol. 2005;32(2):123-9.

14. Susin C, Oppermann R, Haugejorden O, Albandar J. Tooth loss and associated risk indicators in an adult urban population from south Brazil. Acta Odontol Scand. 2005;63(2):8593.

15. De Stefani E, Deneo-Pellegrini H, Boffetta P, Brennan P, Ronco A, Gutiérrez L, et al. Cigarette smoking and risk of large cell carcinoma of the lung: a case-control study in Uruguay. Lung Cancer. 2004;43(3):267-74.

16. Muwonge R, Ramadas K, Sankila R, Thara S, Thomas G, Vinoda J, et al. Role of tobacco smoking, chewing and alcohol drinking in the risk of oral cancer in Trivandrum, India: a nested case-control design using incident cancer cases. Oral Oncol. 2008;44(5):446-54.

17. Heinen M, Verhage B, Goldbohm R, van den Brandt P. Active and passive smoking and the risk of pancreatic cancer in the Netherlands Cohort Study. Cancer Epidemiol Biomarkers Prev. 2010;19(6):1612-22.

18. Jeffcoat M, Geurs N, Reddy M, Cliver S, Goldenberg R, Hauth J. Periodontal infection and preterm birth: results of a prospective study. J Am Dent Assoc. 2001;132(7):875-80.

19. Siqueira F, Cota L, Costa J, Haddad J, Lana A, Costa F. Intrauterine growth restriction, low birth weight, and preterm birth: adverse pregnancy outcomes and their association with maternal periodontitis. J Periodontol. 2007;78(12):2266-76.

20. Kielbassa A, Hinkelbein W, Hellwig E, Meyer-Lückel H. Radiation-related damage to dentition. Lancet Oncol. 2006;7(4):326-35.

21. Mathews S, Kurien B, Scofield R. Oral manifestations of Sjögren's syndrome. J Dent Res. 2008;87(4):308-18. 
22. Oliver R, Tervonen T. Periodontitis and tooth loss: comparing diabetics with the general population. J Am Dent Assoc. 1993;124(12):71-6.

23. Dalla Vecchia C, Susin C, Rösing C, Oppermann R, Albandar $\mathrm{J}$. Overweight and obesity as risk indicators for periodontitis in adults. J Periodontol. 2005;76(10):1721-8.

24. Scheinin A, Mäkinen K, Ylitalo K. Turku sugar studies. V. Final report on the effect of sucrose, fructose and xylitol diets on the caries incidence in man. Acta Odontol Scand. 1976;34(4):179-216.

25. Harris R. Biology of the children of Hopewood House, Bowral, Australia. 4. Observations on dental caries experience extending over five years (1957-61). J Dent Res. 1963;42:138799.

26. Newbrun E, Hoover C, Mettraux G, Graf H. Comparison of dietary habits and dental health of subjects with hereditary fructose intolerance and control subjects. J Am Dent Assoc. 1980;101(4):619-26.

27. Von der Fehr F, Löe H, Theilade E. Experimental caries in man. Caries Res. 1970;4(2):131-48.

28. Sreebny L. The sugar-caries axis. Int Dent J. 1982;32(1):112.

29. Burt B, Pai S. Sugar consumption and caries risk: a systematic review. J Dent Educ. 2001;65(10):1017-23.

30. Zero D. Sugars - the arch criminal? Caries Res. 2004;38(3):27785.

31. Selwitz R, Ismail A, Pitts N. Dental caries. Lancet. 2007;369(9555):51-9.

32. Sheiham A. Dietary effects on dental diseases. Public Health Nutr. 2001;4(2B):569-91.

33. Holmen L, Thylstrup A, Artun J. Clinical and histological features observed during arrestment of active enamel carious lesions in vivo. Caries Res. 1987;21(6):546-54.

34. Mascarenhas A. Oral hygiene as a risk indicator of enamel and dentin caries. Community Dent Oral Epidemiol. 1998;26(5):331-9.

35. Treasure E, Kelly M, Nuttall N, Nunn J, Bradnock G, White D. Factors associated with oral health: a multivariate analysis of results from the 1998 Adult Dental Health survey. Br Dent J. 2001;190(2):60-8.

36. Tagliaferro E, Ambrosano G, Meneghim MC, Pereira A. Risk indicators and risk predictors of dental caries in schoolchildren. J Appl Oral Sci. 2008;16(6):408-13.

37. Axelsson P, Lindhe J. The effect of a preventive programme on dental plaque, gingivitis and caries in schoolchildren. Results after one and two years. J Clin Periodontol. 1974;1(2):12638.

38. Maltz M. Efeito de um programa de higiene oral sobre gengivite e cárie dental em escolares. Porto Alegre: Federal University of Rio Grande do Sul; 1976.

39. Axelsson P, Nyström B, Lindhe J. The long-term effect of a plaque control program on tooth mortality, caries and peri- odontal disease in adults. Results after 30 years of maintenance. J Clin Periodontol. 2004;31(9):749-57.

40. Kay E, Locker D. Oral health promotion and caries prevention. Prim Dent Care. 1999;6(1):35-7.

41. Hujoel P, Cunha-Cruz J, Banting D, Loesche W. Dental flossing and interproximal caries: a systematic review. J Dent Res. 2006;85(4):298-305.

42. Bergenholtz A, Brithon J. Plaque removal by dental floss or toothpicks. An intra-individual comparative study. J Clin Periodontol. 1980;7(6):516-24.

43. Maltz M, Carvalho J. Diagnóstico da doença cárie. In: ABOPREV: Promoção de saúde bucal. São Paulo: Artes Médicas; 2003. p. 69-87.

44. Llodra J, Bravo M, Delgado-Rodriguez M, Baca P, Galvez R. Factors influencing the effectiveness of sealants--a meta-analysis. Community Dent Oral Epidemiol. 1993;21(5):261-8.

45. Mejàre I, Lingström P, Petersson L, Holm A, Twetman S, Källestål C, et al. Caries-preventive effect of fissure sealants: a systematic review. Acta Odontol Scand. 2003;61(6):321-30.

46. Beiruti N, Frencken J, van 't Hof M, van Palenstein Helderman W. Caries-preventive effect of resin-based and glass ionomer sealants over time: a systematic review. Community Dent Oral Epidemiol. 2006;34(6):403-9.

47. Griffin S, Oong E, Kohn W, Vidakovic B, Gooch B, Bader J, et al. The effectiveness of sealants in managing caries lesions. J Dent Res. 2008;87(2):169-74.

48. Ahovuo-Saloranta A, Hiiri A, Nordblad A, Mäkelä M, Worthington H. Pit and fissure sealants for preventing dental decay in the permanent teeth of children and adolescents. Cochrane Database Syst Rev. 2008(4):CD001830.

49. Kidd E. The Cartwright Prize. Caries removal and the pulpodentinal complex. Dent Update. 2000;27(10):476-82.

50. Handelman S, Buonocore M, Heseck D. A preliminary report on the effect of fissure sealant on bacteria in dental caries. J Prosthet Dent. 1972;27(4):390-2.

51. Handelman S, Buonocore M, Schoute P. Progress report on the effect of a fissure sealant on bacteria in dental caries. J Am Dent Assoc. 1973;87(6):1189-91.

52. Jeronimus DJ, Till M, Sveen O. Reduced viability of microorganisms under dental sealants. ASDC J Dent Child. 1975;42(4):275-80.

53. Handelman S, Washburn F, Wopperer P. Two-year report of sealant effect on bacteria in dental caries. J Am Dent Assoc. 1976;93(5):967-70.

54. Going R, Loesche W, Grainger D, Syed S. The viability of microorganisms in carious lesions five years after covering with a fissure sealant. J Am Dent Assoc. 1978;97(3):455-62.

55. Mertz-Fairhurst E, Schuster G, Williams J, Fairhurst C. Clinical progress of sealed and unsealed caries. Part I: Depth changes and bacterial counts. J Prosthet Dent. 1979;42(5):521-6.

56. Oong E, Griffin S, Kohn W, Gooch B, Caufield P. The effect of dental sealants on bacteria levels in caries lesions: a review 
of the evidence. J Am Dent Assoc. 2008;139(3):271-8; quiz 357-8.

57. Mertz-Fairhurst E, Call-Smith K, Shuster G, Williams J, Davis Q, Smith C, et al. Clinical performance of sealed composite restorations placed over caries compared with sealed and unsealed amalgam restorations. J Am Dent Assoc. 1987;115(5):689-94.

58. Mertz-Fairhurst EJ, Curtis JW Jr, Ergle JW, Rueggeberg FA, Adair SM. Ultraconservative and cariostatic sealed restorations: results at year 10. J Am Dent Assoc. 1998;129(1):5566.

59. King JB Jr, Crawford JJ, Lindahl RL. Indirect pulp capping: a bacteriologic study of deep carious dentine in human teeth. Oral Surg Oral Med Oral Pathol. 1965;20(5):663-9.

60. Jordan R, Suzuki M. Conservative treatment of deep carious lesions. J Can Dent Assoc. 1971;37(9):337-42.
61. Magnusson BO, Sundell SO. Stepwise excavation of deep carious lesions in primary molars. J Int Assoc Dent Child. 1977;8(2):36-40.

62. Massler M. Treatment of profound caries to prevent pulpal damage. J Pedod. 1978;2(2):99-105.

63. Bjorndal L, Larsen T, Thylstrup A. A clinical and microbiological study of deep carious lesions during stepwise excavation using long treatment intervals. Caries Res. 1997;31(6):4117.

64. Bjorndal L, Larsen T. Changes in the cultivable flora in deep carious lesions following a stepwise excavation procedure. Caries Res. 2000;34(6):502-8.

65. Maltz M, de Oliveira EF, Fontanella V, Bianchi R. A clinical, microbiologic, and radiographic study of deep caries lesions after incomplete caries removal. Quintessence Int. 2002;33(2):151-9. 